\section{The William J. Cunliffe Scientific Awards}

The William J. Cunliffe Scientific Awards aim to recognize and encourage innovative and outstanding research in the areas of endocrine dermatology and skin pharmacology conferring great benefit upon understanding the function of the pilosebaceous unit as well as the pathophysiology and treatment of its diseases.

Through their work, William J. Cunliffe laureates have to focus by their discoveries worldwide attention on

(1) the significance of the skin, and especially of the pilosebaceous unit, as hormone target and endocrine organ, and

(2) the development of new molecules to target skin diseases as well as the understanding of the molecular action of therapeutic compounds.

The awards endowed by a gift from Galderma and administered by the Department of Dermatology, the Free University of Berlin, were established in 2001 in honor of the lifetime scientific work of Prof. emer. William J. Cunliffe, MD.

\section{The William J. Cunliffe Lectureship}

The William J. Cunliffe Lectureship is a symbol of the admiration of a scientist's lifetime achievement, a symbol of eminence, and demonstrates that the recipient's accomplishments and contributions to endocrine dermatology and skin pharmacology, especially in the area of the pilosebaceous unit, are considered exceptional by those of his colleagues who are best able to judge their value. No restrictions are placed on a candidate's citizenship or country of residency.

The award was presented for the first time in 2001 to Prof. William J. Cunliffe for his enormous contribution in clinical and experimental dermatological research at a ceremony during the 10th Congress of the European Academy of Dermatology and Venereology in Munich on October 10-14, 2001.

William J. Cunliffe Lectureship laureates receive a $€ 15,000$ award and are presented a William J. Cunliffe medallion at ceremonies on the occasion of the annual congresses of the European Academy of Dermatology and Venereology. The award also includes an invitation to deliver a lecture dealing with the broad spectrum of endocrine dermatology and skin pharmacology at a meeting designated by the Executive Committee, travel expenses to the meeting at which the lecture is given, and 15 free pages for publication of the lecture in the journal Dermatology. The publication of the lecture shall be arranged as agreeable to the lecturer and the Executive Committee.

The William J. Cunliffe Lectureship will be presented biannually.

The William J. Cunliffe Scientific Awards are supported by Galderma.

\section{The William J. Cunliffe Prize}

The William J. Cunliffe Prize awards innovative and outstanding research in the areas of endocrine dermatology and skin pharmacology conferring great benefit upon understanding the function of the pilosebaceous unit as well as the pathophysiology and treatment of its diseases. No restrictions are placed on a candidate's citizenship or country of residency.

The award will be presented for the first time in 2002 at a ceremony during the 11th Congress of the European Academy of Dermatology and Venereology in Prague, Czech Republic, on October 2-6, 2002.

William J. Cunliffe Prize laureates receive a $€ 12,500$ award and a certificate citing the contribution made by the recipient at ceremonies on the occasion of the annual congresses of the European Academy of Dermatology and Venereology. The prize recipient shall be invited to present a paper on the subject for which the prize was granted at a meeting designated by the Executive Committee. Travel expenses incurred by the recipient to attend the meeting are reimbursed from funds provided by Galderma. The laureates will also be invited to write a review of their work to be published in the journal Dermatology.

The William J. Cunliffe Prize will be presented biannually in alteration with the William J. Cunliffe Lectureship.

\section{The William J. Cunliffe Scientific Awards Executive Committee}

An ad hoc William J. Cunliffe Scientific Awards Executive Committee - constituted of: Prof. Dr. Christos C. Zouboulis, Berlin, Germany (Chair); Prof. Dr. Harald P.M. Gollnick, Magdeburg, Germany (Vice-Chair); Prof. Yasuo Asada, MD, Osaka, Japan; Prof. George Cotsarelis, MD, PhD, Philadelphia, Pa., USA; Prof. Brigitte Dréno, Nantes, France; Prof. Dr. Ana Kaminsky, Buenos Aires, Argentina; Prof. Terence Kealey, MD, Buckingham, UK; Prof. Jean-Hilaire Saurat, Geneva, Switzerland; Prof. Diane Thiboutot, MD, Hershey, Pa., USA - judges the nominees and selects the awardees in June of each year. The awards are presented at a special ceremony during the Congress of the European Academy of Dermatology and Venereology of the same year.

For nomination guidelines please contact:

Prof. Dr. Christos C. Zouboulis

Chair of the Executive Committee

The William J. Cunliffe Scientific Awards

Department of Dermatology

University Medical Center Benjamin Franklin

Free University of Berlin

Fabeckstrasse 60-62

D-14195 Berlin (Germany)

Tel. +49 3084456910

Fax +49 3084456908

E-Mail zouboulis@medizin.fu-berlin.de

\section{KARGER}

Fax +4161306 1234

E-Mail karger@karger.ch

www. karger.com
(C) 2002 S. Karger AG, Basel

$1018-8665 / 02 / 2042-0163 \$ 18.50 / 0$

Accessible online at:

www.karger.com/journals/drm 
The William J. Cunliffe Scientific Awards 2002

William J. Cunliffe Prize 2002

Eastern European Prize for Acne Research 2002

The William J. Cunliffe Scientific Awards were presented in 2001 for the first time. Prof. William J. Cunliffe, Leeds, UK, received the William J. Cunliffe Lectureship for his long innovative scientific career in the fields of endocrine dermatology and skin pharmacology of hair and sebaceous glands. The presentation of the Award accompanied by $€ 15,000$ took place during the 10th Congress of the European Academy of Dermatology and Venereology in Munich on October 11, 2001.

In the year 2002, the following awards will be presented:

(1) The William J. Cunliffe Prize for innovative excellent research in the fields of endocrine dermatology and skin pharmacology of hair and sebaceous glands. All scientists working worldwide are eligible to participate. The award is accompanied by $€ 12,500$. Research projects, manuscripts, publications and applications for a patent can be submitted.
(2) The Eastern European Prize for Acne Research will be awarded to a young scientist (up to 35 years old) from the Eastern European countries in order to perform research in the area of acne at a renowned laboratory. The prize is accompanied by $€ 15,000$.

The application forms are provided by the Awards secretariat. Any applications for both awards must be submitted by May 31, 2002, to the William J. Cunliffe Scientific Awards, attention Prof. Dr. Christos C. Zouboulis, Department of Dermatology, University Medical Center Benjamin Franklin, Free University of Berlin, Fabeckstrasse 60-62, D-14195 Berlin (Germany).

The laureate of the William J. Cunliffe Prize is obliged to publish a paper suitable to the journal Dermatology. The decisions are taken by the Executive Committee of the William J. Cunliffe Scientific Awards. Nominations could be made by the president of the nominee's university, faculty dean or by the CEO of the nominee's institution or company. Self-nominations are not accepted. 